\title{
Sudden death and suicide: a comparison of brain weight
}

\author{
S. J. HAMILTON and R. F. T. McMAHON
}

\section{Background Recent evidence suggests that the brain weight of individuals over the age of 60 who commit suicide is significantly higher than in those who die of natural causes.}

Aims Toascertain whether brain weight is different in people of a younger age who commit suicide than in those who die accidentally.

\section{Method A retrospective review of post-mortem reports collecting height, weight and brain weight in 100 suicide victims ( 87 males, mean age 38.5 years) and 100 age/gender-matched controls who died accidentally or of natural causes (87 males, mean age 38.7 years). Comparison by $t$-test was made of brain weight in isolation as well as brain weight corrected for height, weight and body mass index.}

\section{Results These results reveal no significant difference in brain weight in suicide cases compared to the general population $(P>0.05)$. The brain weight of those who died by hanging was significantly higher than of those who died by overdose.}

Conclusions Whatever the significant neuropsychiatric elements are that influence suicidal behaviour, they do not consistently affect brain weight in the population studied.

Declaration of interest None.
Salib \& Tadros (2000) recently suggested that brain weight in people over 60 years of age who commit fatal self-harm is significantly higher than in those who die of natural causes. This was true for all suicide methods but there was no difference between suicide modes. Brain weight, structure and volume have been examined in several conditions. Courchesne et al (1999) reported that in 21 autopsy cases of autism, 17 brains were of normal weight, with 1 being microcephalic and another megalencephalic. Brown et al (1986) found that in schizophrenia, brain weight was reduced compared with age and gendermatched controls with affective disorders. Bruton et al (1990) showed that the brain weight of people with schizophrenia was lower than normal controls, even excluding other pathologies, whereas Hakim \& Mathieson (1979) found similar results in Parkinson's disease. Mueller et al (1998), using quantitative volumetric magnetic resonance imaging, reported that the widespread loss of brain volume in the aged is most likely to be due to the onset of preclinical dementia, and that the healthy elderly had a low rate of brain volume reduction. Regarding suicide, Szigethy et al (1994) found that the left adrenal weight is increased in suicide victims and several groups. Roy (1992) and Yehuda et al (1988) have suggested that there is hypothalamic-pituitary-axis dysregulation in severe depression and suicidal patients. Schroder \& Saternus (1983) found that brain weight was higher in victims of hanging in the general population.

Following the findings of Salib \& Tadros (2000) we thought that it would be valuable to look at brain weight in suicide in a wider age range and also to compare suicide victims with those who died both accidentally and of natural causes. This would allow us to ascertain whether there was a difference in brain weight between those who have suicidal intent and those who do not. Methods of suicide could also be compared to see if these altered brain weight.

\section{METHOD}

\section{Case selection}

Suitable cases were selected using the postmortem reports submitted to the HM Coroner for the City of Manchester during the period 1 January 1998 to 31 December 2000. Age, sex, height, weight, brain weight and cause of death were recorded. Body weight was measured unclothed and the brain was weighed, unfixed, on a selfcalibrating digital balance (Model A \& D FS-6K) at the time of removal from the cranium. The cases selected were then divided into suicidal deaths and age/ gender-matched controls. For the purposes of this study, excess ethanol or methadone were considered to be accidental unless there was strong evidence in the clinical history to the contrary. Any cases in which all of these parameters were not present were discarded.

\section{Comparison of data}

Average brain weight in each group was then compared. Body mass index (BMI), defined as weight (in $\mathrm{kg}$ )/height ${ }^{2}\left(\mathrm{~m}^{2}\right)$ was calculated and a comparison of the brain weight/BMI was made in the cases and controls. The ratios of brain weight/weight and brain weight/height were also compared. Standard deviation (s.d.) and 95\% confidence intervals were calculated for each of these parameters. Mean differences were calculated and a paired $t$-test was used to ascertain whether the difference was significant. This was carried out for the entire case-control group but also separately for the two main modes of suicide, hanging and overdose. Analysis could not be performed on the other modes as the sample sizes were too small. Cases of death by accidental excess substance ingestion were also analysed separately. They were compared with both suicide cases and death by natural causes to assess whether there was any difference in brain weight depending on whether death was natural or unnatural, and whether unnatural death was intentional or accidental. Suicide cases were also compared to the naturalcauses-only (excluding accidental overdose) group and the major subgroups of the suicide cases were compared to ascertain the effect of the method of death on brain weight. 
Table I Causes of death for suicide victims

\begin{tabular}{lc}
\hline Cause of death & $\begin{array}{c}\text { Number of } \\
\text { cases }\end{array}$ \\
\hline Carbon monoxide poisoning & 2 \\
Drowning & 3 \\
Hanging & 53 \\
Overdose & 41 \\
Struck by train & 1 \\
\hline
\end{tabular}

\section{RESULTS}

\section{Demographics}

There were 100 cases and 100 age- and gender-matched controls that contained all of the data required. In each group, six of the patients were over 60 years old. Causes of death are given in Tables 1 and 2. Mean age for suicide victims was 38.5 years compared with 38.7 years for other cases. In both groups there were 87 males and 13 females.

Table 2 Causes of death for control population

\begin{tabular}{lclc}
\hline Cause of death & $\begin{array}{c}\text { Number of } \\
\text { cases }\end{array}$ & Cause of death & Number of cases \\
\hline Cardiac $^{1}$ & 17 & Respiratory $^{2}$ & 12 \\
Gastrointestinal $^{3}$ & 4 & Hepatic $^{4}$ & 10 \\
Neoplasia $^{5}$ & 4 & Metabolic $^{6}$ & 2 \\
Neurological $^{7}$ & 7 & Septicaemia & 2 \\
Substance excess/misuse $^{\text {Acute renal failure }}$ & 35 & Multiple injuries & 4 \\
\hline
\end{tabular}

I. Cardiac includes left ventricular failure (three), myocardial ischaemia (four), myocardial infarction (two), arrhythmia (three), cardiomyopathy (two), endocarditis (one), viral myocarditis (one) and bridging coronary arteries (one).

2. Respiratory includes pneumonia (six), aspiration pneumonia (one), pulmonary thromboembolus (one), aspiration of gastric contents (one), haemothorax (one) and asthma (two).

3. Gastrointestinal includes Mallory-Weiss tear (one), sigmoid volvulus (one), variceal bleed (one) and perforated diverticulum (one)

4. Hepatic includes alcoholic liver disease (two), steatosis (four) and hepatic failure (four).

5. Neoplasia includes carcinomatosis (one), acute myeloid leukaemia (one), testicular carcinoma (one) and mesothelioma (one).

6. Metabolic includes diabetic ketoacidosis (one) and hypoglycaemia (one).

7. Neurological includes epilepsy (five), vasovagal (one) and cerebral oedema (one).

\section{Brain weights}

Average brain weight in suicide cases was $1449 \mathrm{~g}$ (s.d. $161 \mathrm{~g}$ ) compared with $1423 \mathrm{~g}$ (s.d. $161 \mathrm{~g}$ ) in the control group. Average brain weight in males was $1468 \mathrm{~g}$ for suicide victims and $1449 \mathrm{~g}$ for the controls. In females, the average brain weights were $1251 \mathrm{~g}$ for suicides and $1322 \mathrm{~g}$ for the controls. BMI was calculated in the standard manner, giving values of $22.24 \mathrm{~kg} / \mathrm{m}^{2}$ for cases and $21.74 \mathrm{~kg} / \mathrm{m}^{2}$ for controls. Thus, when brain weight was compared to BMI, the result in suicide victims was $67.37 \mathrm{~g} / \mathrm{kg} / \mathrm{m}^{2}$ (s.d. 14.1) and $68.1 \mathrm{~g} / \mathrm{kg} / \mathrm{m}^{2}$ in the control group (s.d. 15.3). Mean brain weight/body weight was 21.2 (s.d. 4.12) in cases and 21.8 (s.d. 5.00) in controls. Mean brain weight/ height was $813 \mathrm{~g} / \mathrm{m}$ in cases (s.d. 76.4) and $805 \mathrm{~g} / \mathrm{m}$ (s.d. 85.1) in controls. The same calculations were performed for the male cases and controls only to exclude bias due to the lower average brain weight in females seen both in this study and in published data (Knight, 1996). These data are summarised in Table 3 and the data for brain weight controlled for BMI are shown in Figure 1.

\section{Comparison of suicide victims and control group}

Comparing brain weights gave a mean difference of $25.71 \mathrm{~g}$ (i.e. on average the

Table 3 Results for the suicide and control groups and their subgroups showing both the overall figures and those for male subjects only

\begin{tabular}{|c|c|c|c|c|c|c|}
\hline Group & $\begin{array}{l}\text { Mean age } \\
\text { years (s.d.) }\end{array}$ & $\begin{array}{c}\text { Mean BMI } \\
\mathrm{kg} / \mathrm{m}^{2} \text { (s.d.) }\end{array}$ & $\begin{array}{c}\text { Mean brain weight } \\
\text { g(s.d.) }\end{array}$ & $\begin{array}{c}\text { Mean (brain wt } / \text { BMI) } \\
\mathrm{g} / \mathrm{kg} / \mathrm{m}^{2} \text { (s.d.) }\end{array}$ & $\begin{array}{c}\text { Mean (brain wt/body wt) } \\
\text { g/kg (s.d.) }\end{array}$ & $\begin{array}{c}\text { Mean (brain wt } / \mathrm{ht} \text { ) } \\
\mathrm{g} / \mathrm{m} \text { (s.d.) }\end{array}$ \\
\hline Suicide cases $(n=100)$ & $38.5(13.8)$ & $22.2(4.1)$ & $1449(161)$ & $67.4(14.1)$ & $21.2(4.1)$ & $813(76.4)$ \\
\hline Suicide cases (males only) $(n=87)$ & $38.4(14.4)$ & $21.7(3.7)$ & $1468(162)$ & $69.4(13.3)$ & $21.5(4.0)$ & $817(79.0)$ \\
\hline Hangings $(n=53)$ & $37.8(16.2)$ & $21.0(3.1)$ & $1480(169)^{*}$ & $71.6(11.5)^{*}$ & $22.2(3.7)^{*}$ & $823(79.2)$ \\
\hline Hangings (males only) $(n=50)$ & $36.4(16.1)$ & $20.9(3.0)$ & $1499(155)^{* *}$ & $73.1(10.8)^{* *}$ & $22.4(3.5)^{* *}$ & $829(77.9)$ \\
\hline Deliberate overdose $(n=4 I)$ & $41.0(10.7)$ & $23.6(4.7)$ & I386 (I50)* & $61.2(14.7)^{*}$ & $20.2(4.8)^{*}$ & $795(81.3)$ \\
\hline $\begin{array}{l}\text { Deliberate overdose (males } \\
\text { only) }(n=30)\end{array}$ & $38.9(10.6)$ & $22.9(4.6)$ & $|42|(\mid 73)^{* *}$ & $64.5(15.9)^{* *}$ & $20.3(4.6)^{* *}$ & $796(81.4)$ \\
\hline Controls $(n=100)$ & $38.7(13.9)$ & $21.7(4.8)$ & $1423(161)$ & $68.1(15.3)$ & $21.8(5.0)$ & $805(85.1)$ \\
\hline Controls (males only) $(n=87)$ & $38.8(14.3)$ & $21.8(4.6)$ & $1449(152)$ & $69.1(17.1)$ & $21.9(5.3)$ & $812(85.2)$ \\
\hline Accidental overdose $(n=35)$ & $33.1(6.5)$ & $21.4(3.6)$ & $1438(139)$ & $68.9(12.4)$ & $21.8(4.7)$ & $807(88.7)$ \\
\hline $\begin{array}{l}\text { Accidental overdose (males } \\
\text { only) }(n=3 \mathrm{I})\end{array}$ & $32.5(5.9)$ & $21.4(3.4)$ & $1455(127)$ & $69.7(12.1)$ & $21.6(4.3)$ & $810(91.5)$ \\
\hline Natural $(n=65)$ & $41.7(15.8)$ & $22.0(5.3)$ & $1416(67.8)$ & $67.6(16.8)$ & $21.8(5.2)$ & $804(83.7)$ \\
\hline Natural (males only) $(n=55)$ & $42.6(16.3)$ & $21.9(5.2)$ & $1444(127)$ & $69.1(17.1)$ & $21.9(5.3)$ & $812(85.2)$ \\
\hline
\end{tabular}

BMI, body mass index; wt, weight; ht, height.

*Difference between overall results for hanging and deliberate overdose groups. $P=0.006$ for brain weight in isolation, $P<0.001$ for brain weight $/ \mathrm{BMI}$ and $P=0.004$ for brain weight $/$ body weight; **difference between hanging and deliberate overdose results for males only. $P=0.047$ for brain weight in isolation, $P=0.013$ for brain weight $/ B M l$ and $P=0.034$ for brain weight/body weight. 


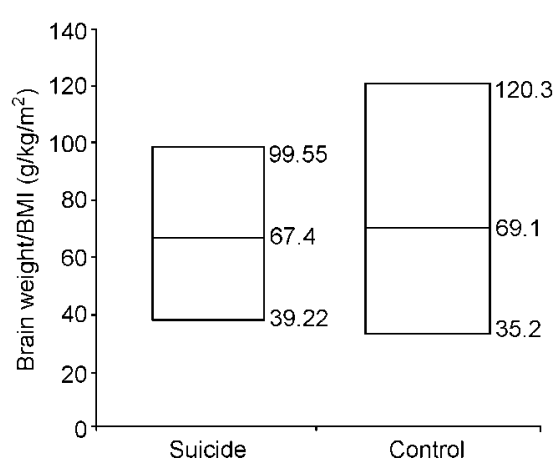

Fig. I Comparison of mean, minimum and maximum brain weights corrected for body mass index for suicide and control groups.

brain weight in suicide victims was $25.71 \mathrm{~g}$ heavier) with an s.d. of $193.4 \mathrm{~g}(P=0.187)$. Similarly, the differences between the brain weights controlled for BMI was 0.70 (s.d. 19.9, $P=0.727)$. Brain weight corrected for weight gave a difference of $0.61 \mathrm{~g} / \mathrm{kg}$ (s.d. 6.79, $P=0.368$ ). Brain weight corrected for height gave a mean difference of $8.45 \mathrm{~g} / \mathrm{m}$ (s.d. $109, P=0.441$ ). There were no significant differences between hangings and overdoses compared with natural deaths, or related to the chosen method and dying accidentally, or between suicidal and accidental overdose.

\section{Comparison of those who committed suicide by hanging and overdose}

However, when hanging victims were compared with those having deliberately overdosed, the difference in brain weight was $92 \mathrm{~g}$ (i.e. the brain in hanging was $92 \mathrm{~g}$ heavier than that in overdose). This was significant with a $P$ value of 0.006 . Controlled for BMI, the difference was $11.4 \mathrm{~g} / \mathrm{kg} / \mathrm{m}^{2}(P<0.001)$ and the difference controlled for total body weight was $2.51 \mathrm{~g} / \mathrm{kg} \quad(P=0.004)$. The difference controlled for height was $29.0 \mathrm{~g} / \mathrm{m}$, but this was not significant. The comparison between hanging and deliberate overdose remained significant when this sample was confined to the males only. In this instance, difference in brain weight was $78 \mathrm{~g}$ $(P=0.047)$. Controlled for BMI, the difference was $8.53 \mathrm{~g} / \mathrm{kg} / \mathrm{m}^{2}(P=0.013)$ and for weight, $2.14 \mathrm{~g} / \mathrm{kg} \quad(P=0.034)$. The brain weight to height difference was $33.0 \mathrm{~g} / \mathrm{m}$, again not significant. The results for the subgroups (corrected for BMI) are shown in Table 3.

\section{DISCUSSION}

\section{General observations}

The data obtained in this study suggest that there is no difference in brain weight between suicide victims and their contemporaries who die suddenly of natural causes or accidentally. This remains true whether brain weight is examined in isolation or if it is corrected to take into account the body habitus. However, the brain weight in victims of hanging is significantly higher than in those who died by deliberate overdose. The absence of a significant difference between accidental substance excess and both the natural causes and suicide groups supports this assertion and also suggests that the ideation of suicide is not related to brain weight, either causally or as a secondary phenomenon. The average brain weight in both suicide and control groups falls within the average range as given by Knight (1996) for both males (1468 g and $1449 \mathrm{~g}$ respectively; normal range $1075-1685 \mathrm{~g}$ for the 30-39 age group) and females $(1322 \mathrm{~g}$ and $1251 \mathrm{~g}$, respectively; normal range 1038-1440 g for this age group).

These results show a slightly different picture to those of Salib \& Tadros (2000). However, the parameters of the current study are also slightly different. We have used natural and accidental deaths as controls to ascertain whether those with suicidal intent have different brain weights to those who do not, and these data would suggest that there is no significant difference between these groups. There could be reasons why brain weight in the older population is higher in suicide victims, such as the presence of preclinical dementia in the control group, which would impair the ability to plan and carry out a suicide attempt. There is also a difference in the ages of patients in our group, with only $6 \%$ being over 60 years old.

\section{Differences in brain weight between methods of suicide}

Because the brain on average weighs $1.4 \%$ of the total body weight, we felt that brain weight looked at in isolation might give misleading results. We have attempted to avoid any bias by looking at brain weight in relation to height, weight and BMI. However, there was no significant difference between the study and control groups. We also compared the results for the different methods of suicide used. It must be noted that the numbers for drowning (three people), carbon monoxide poisoning (two people) and train collision (one person) are very low and no attempt at statistical analysis has been attempted for these methods. More cases were available for the hanging and overdose groups and our results suggest that the brain weight in hanging is higher than that in overdose. If this difference in brain weight had been because of pre-mortem changes one would expect to see a significant difference for all modes of suicide. Therefore, we suggest that the observed difference results from congestion and oedema occurring during the act of hanging itself rather than a structural difference in the brain before a successful suicide attempt.

\section{Possible confounding factors}

Of course, there is the potential for several confounding factors. In the elderly population, degenerative brain diseases are more prevalent. In the younger group, it was difficult to collect a control population who died of completely natural causes, and even of those who do, the potential effect of disease on brain weight is unknown, although presumed to be slight. In the case of unnatural deaths (accidental overdoses and road traffic accidents), we do not know the effect of mode of death on brain weight. Many brains show a degree of hypoxic damage, which is probably an agonal event.

\section{Future developments}

Salib \& Tadros (2000) recommended establishing a national database of findings following routine neuropathological examination of autopsy. In the current climate in autopsy pathology, this will require close cooperation between clinicians and pathologists to ensure that properly informed consent is obtained from relatives, notwithstanding the fact that the majority of autopsies in the context of suicide are performed within the coronial system. However, much useful information has been and can be gained from detailed structural and neurochemical studies of brains removed at autopsy from a range of psychiatric conditions, including those leading to suicide. Although the current study indicates that there are no differences in brain weight in a younger group of suicides (compared with the findings of Salib \& Tadros, 2000), this should not 
prevent further studies on brains from this group of individuals.

From our investigations, it would appear that whatever makes a person decide to take their own life does not appear to be related to the weight of the brain.

\section{ACKNOWLEDGEMENTS}

We thank the mortuary technicians (E. Bryson, S. Cunningham, J. Graham and P. Hyde) at Manchester Royal Infirmary and L. M. Gorodkin, HM Coroner (Central Manchester), for his permission to report on cases performed in his jurisdiction and for access to his records.

\section{REFERENCES}

Brown, R., Colter, N., Corsellis, J. A., et al (1986) Postmortem evidence of structural brain changes in schizophrenia. Differences in brain weight, temporal horn area, and parahippocampal gyrus compared with affective disorder. Archives of General Psychiatry, 43, $36-42$

Bruton, C. J., Crow, T. J., Frith, C. D., et al (1990) Schizophrenia and the brain: a prospective cliniconeuropathological study. Psychological Medicine, 20, 285-304.

Courchesne, E., Muller, R. A. \& Saitoh, O. (1999) Brain weight in autism; normal in the majority of cases, megalencephalic in rare cases. Neurology, 52, 1057-1059.

Hakim, A. M. \& Mathieson, G. (1979) Dementia in Parkinson disease: a neuropathologic study. Neurology, 29, 1209-1214.

Knight, B. (1996) Forensic Pathology, 2nd edition. London: Arnold/Oxford University Press.

Mueller, E. A., Moore, M. M., Kerr, D. C., et al (1998) Brain volume preserved in the healthy elderly through the eleventh decade. Neurology, 5I, 1555-1562.

Roy, A. (1992) Hypothalamic pituitary axis function and suicidal behaviour in depression. Biological Psychiatry, 32. 812-816.

\section{CLINICAL IMPLICATIONS}

Brain weight does not appear to be significantly higher in those with suicidal ideation than in those who die naturally or accidentally.

- Higher brain weight in elderly suicide victims could be due to factors other than the fact that the victim is suicidal.

- The method of suicide is a factor in brain weight at post-mortem.

\section{LIMITATIONS}

- Retrospective study.

- Post-mortems performed by several pathologists.

- Can be difficult to assess suicidal intent after the fact. Coroners work on "balance of probabilities', not 'beyond reasonable doubt'.

S. J. HAMILTON, MB, ChB, Department of Histopathology, Manchester Royal Infirmary, UK; R. F. T. McMAHON, MD, Department of Histopathology, Manchester Royal Infirmary, UK and Laboratory Medicine Academic Group, University of Manchester, UK

Correspondence: Ray McMahon, Manchester Royal Infirmary, Oxford Road, Manchester MI3 9WL, UK. E-mail: ray.mcmahon@man.ac.uk

(First received 24 July 200I, final revision 7 February 2002, accepted 7 February 2002)

Salib, E. \& Tadros, G. (2000) Brain weight in suicide An exploratory study. British Journal of Psychiatry, $\mathbf{1 7 7}$ 257-261.

Schroder, R. \& Saternus, K. S. (1983) Congestion in the area of the head and changes in the brain caused by suicidal hanging death. Zeitschrift für Rechtsmedizin, 89, $247-265$.
Szigethy, E., Conwell, Y., Forbes, N.T., et al (1994) Adrenal weight and morphology in victims of completed suicide. Biological Psychiatry, 36, 374-380.

Yehuda, R., Southwick, S. M., Ostroff, R. B., et al (1988) Neuroendocrine aspects of suicidal behaviour. Neurology Clinics, 6, 83-102. 